\title{
Successful translocation of the threatened New Zealand root-holoparasite Dactylanthus taylorii (Mystropetalaceae)
}

\author{
Sebastian Avi Holzapfel · John Dodgson • \\ Maheshwaran Rohan
}

Received: 28 June 2015/ Accepted: 16 December 2015/Published online: 28 December 2015

(C) The Author(s) 2015. This article is published with open access at Springerlink.com

\begin{abstract}
The conservation and translocation of threatened holoparasitic flowering plants provide added challenges due to their complete host dependency and often large knowledge gaps of their autecology. Here, we present the first successful, quantified field trial to establish from seed populations of dactylanthus (Dactylanthus taylorii, Mystropetalaceae), a threatened New Zealand endemic rootholoparasitic angiosperm. Establishment was
\end{abstract}

Communicated by Dr. Thomas Abeli and Prof. Kingsley Dixon.

Electronic supplementary material The online version of this article (doi:10.1007/s11258-015-0556-7) contains supplementary material, which is available to authorized users.

S. A. Holzapfel $(\bowtie)$

Science and Technical Group, Department of

Conservation, Private Bag 3072, Hamilton 3240,

New Zealand

e-mail: aholzapfel@doc.govt.nz

J. Dodgson

71 C Waiwera Street, Kawhia, Te Awamutu 3889,

New Zealand

M. Rohan

Department of Biostatistics and Epidemiology,

Auckland University of Technology,

Private Bag 92006, Auckland 1142, New Zealand monitored at four sites at Waipapa, Pureora Forest Park. The impact of two different sowing methods (broad- and central-sown), canopy state (as a proxy for soil moisture levels) and three dominant host species were tested. Establishment of dactylanthus was confirmed in 22 out of 24 plots 10 years after sowing, with earliest emergence after 4 years. Average and maximum inflorescence numbers per plot were similar to those of protected wild populations. The only opencanopy site performed worse in comparison with a closed-canopy site sharing the same dominant host species; differences in root availability and survival of the desiccation-sensitive seeds were regarded as the most likely explanations. Host species dominance had a significant impact on inflorescence numbers, indicating host preference in the species despite a wide host range. In contrast to longer-established wild populations, most of which are male-biased, female inflorescences strongly outnumbered males, considered as evidence of environmental sex determination and sex-switching of individuals. Findings from this study have increased our knowledge of the biology of dactylanthus, confirmed translocation as an effective tool in the conservation of the species and should be applicable for the protection of threatened parasitic plants species elsewhere in the world.

Keywords Translocation - Parasitic plants . Conservation $\cdot$ Sex determination $\cdot$ Balanophoraceae s.lat. - Mystropetalaceae $\cdot$ Host preference $\cdot$ Sowing method - Dactylanthus taylorii $\cdot$ New Zealand 


\section{Introduction}

Despite a high percentage of rare or threatened species among holoparasitic angiosperms globally, little research has been undertaken on the establishment of populations (Marvier 1996), even though the need has been recognised. This seems due to the complication of having to consider both the species and their hosts in any management (Arunachalam et al. 2004; Kuijt 1969; Marvier and Smith 1997) and because knowledge of basic aspects such as habitat and host requirements are not well understood for many of the holoparasitic families (Atsatt 1983; Bolin et al. 2009; Musselman and Press 1995; Pennings and Callaway 2002) apart from agricultural crop-damaging taxa (Mescher et al. 2009; Press and Graves 1995; Weber and Forstreuter 1987). While some generalisations will be justified, a focus on control and eradication of common weed species does usually not provide sufficient understanding of the life cycle and requirements of rare and threatened taxa (Atsatt 1983). As a consequence, conservation of holoparasitic plants has focussed largely on the protection of existing populations and their host communities (Arunachalam et al. 2004; Marvier and Smith 1997; Olanya and Eilu 2009), rather than on re-establishing a species over its former range or into protected habitat.

Despite earlier optimism about the ease of experimental germination and cultivation of holoparasitic plants (Heinricher 1907; Kuijt 1969), only very few germination trials have been described in the literature (see Holzapfel 2001). Cultivation trials have been restricted to glasshouse experiments (Heinricher 1917b; Watanabe 1942) and out-plantings of host trees infected in cultivation (Ecroyd 1996; Lawrence and Kaye 2008). Host presence was usually assumed critical for germination despite evidence to the contrary (Holzapfel 2001).

Here we report results of the first formal trial to introduce a holoparasitic plant, dactylanthus (Dactylanthus taylorii Hook f., Mystropetalaceae ${ }^{1}$ ) into the wild on a population scale, following successful glasshouse experiments and small-scale ex situ plantings (Ecroyd 1996; Holzapfel and Dodgson 2004). We

\footnotetext{
$\overline{1 \text { Dactylanthus }}$ was until recently considered part of the family of root holoparasites Balanophoraceae. New data have shown the family to be polyphyletic, and Dactylanthus has been transferred, together with Hachettea and Mystropetalon, into the reinstated family of Mystropetalaceae Hook.f. (Su et al. 2015).
}

explore whether the species can be established in the field from seed, the influence of local site conditions, host preference and sowing methods on establishment success and productivity of populations, and the gender ratio of young populations. This research is, to the best of our knowledge, also the first long-term study of known-age plants of any member of the Balanophoraceae s.l.

\section{Materials and methods}

Study species

Dactylanthus is a holoparasitic flowering plant endemic to New Zealand. Its distributional area today is $<5 \%$ of levels prior to the arrival of humans (Ministry for the Environment 2007), a result of habitat change and introduced browsing mammals (Ecroyd 1996; Holzapfel 2001). The species is classified as threatened (Nationally Vulnerable-Conservation Dependent) (de Lange et al. 2013) and a national management programme has been in place since 1993 (Holzapfel et al. 2002; La Cock et al. 2005).

The morphology and reproductive biology of dactylanthus have been described in detail elsewhere (Ecroyd 1996; Holzapfel 2001; Moore 1940) and are summarised here only as they relate to the present study.

Dactylanthus is a root parasite, its main body consisting of a mainly subterranean, perennial tuber (Fig. 1a). In the flowering season between January and May (i.e. roughly the southern hemisphere autumn), one or more capitulate inflorescences grow from the tuber to just above the forest floor, with each capitulum enclosing several thousand minute flowers (Fig. 1b). Inflorescences contain predominantly only flowers of one sex, with mixed-sex (monoecious) inflorescences being rare (Cheeseman 1906, 1914; Ecroyd 1996; Holzapfel 2001).

The species is generally considered dioecious (Ecroyd 1996), however, as tubers often form close aggregates the identification of individual plants is difficult (Cheeseman 1906, 1920; Holzapfel 2001). Sex distribution in established populations is usually strongly male-biased; a ratio of 5:1 male to female inflorescences was observed in one population over several years (Ecroyd 1996). 

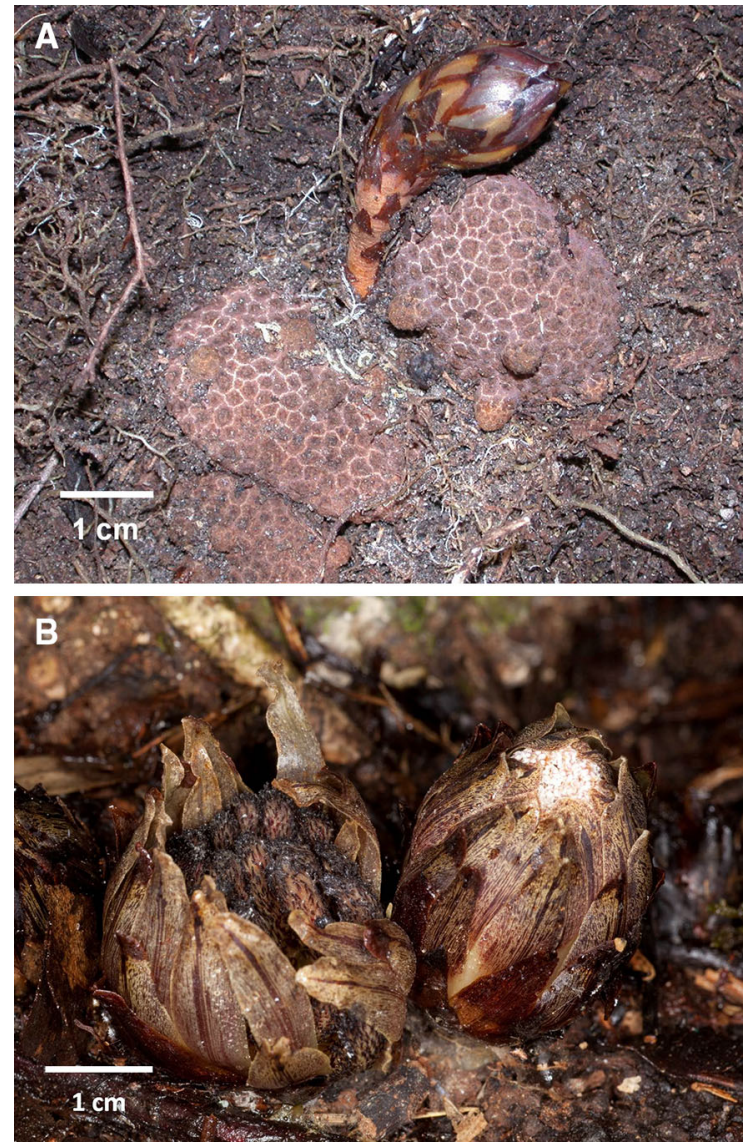

Fig. 1 a A group of young dactylanthus tubers in their first year of emergence in 2004, 5 years after sowing. The tuber surfaces show the characteristic patterning of angular platelets surrounded by lighter boundary lines. Inflorescence buds in early stages of development and one mature inflorescence close to anthesis are visible. Leaf litter and some soil have been removed to expose tubers for the photograph. b Female (left) and male inflorescence of dactylanthus. In the female inflorescence several columnar spadices beset with dark, hair-like styles of individual flowers are exposed by the recurving bracts. In the male inflorescence, white globular anthers of individual male flowers are exposed at the apex. Photos S. A. Holzapfel (a); D. Mudge, Nga Manu Trust (b)

Pollination of the nectar-rich, strongly scented inflorescences is today carried out by the endemic short-tailed bat Mystacina tuberculata Gray and introduced rodents (Ecroyd 1996; Meys 2003). Other native extant or extinct fauna species may also act, or have acted in the past, as pollinators (Wood et al. 2012).

Fruits, small yellow to brown drupes $<2 \mathrm{~mm}$ in length, develop over the following 6-8 months after fertilisation. The testa-less seed remains enclosed in the hard endocarp or 'stone' of the drupe, and both form the diaspore. Although botanically somewhat inaccurate, the entire diaspore will be referred to in the following as seed.

Seed dispersal is predominantly short-range (centimetres to metres); individual seed washed off the infructescence by rain or entire infructescences detached from the tuber are moved by gravity and possibly surface water (Holzapfel 2001). Leaf-litter accumulation and small soil disturbance, e.g. through bird scratching and earthworms (Meys 2003), bring seeds over time into the upper root zone of host trees. Long-distance dispersal by animals has not yet been demonstrated through native species (Ecroyd 1996; Holzapfel 2001). Introduced ship rats (Rattus rattus L.) and possibly possums (Trichosurus vulpecula Kerr) eat and pass viable seed (Holzapfel 2001; Meys 2003).

Seeds are desiccation-sensitive and can stay dormant in sufficiently moist soil for several years, aggregating in dense seedbanks close to infructescence-bearing plants; seeds are therefore dispersed predominantly in time rather than space (Holzapfel 2001). In contrast to common statements in the literature concerning holoparasitic flowering plants (Heinricher 1907; Joel et al. 1995; Kuijt 1969; Shen et al. 2005; Stewart and Press 1990), seeds of dactylanthus do not require a host stimulant to germinate, rather, a proportion of seeds within a seedbank will germinate each year (Holzapfel 2001). Alongside sexual reproduction, D. taylorii is also capable of reproducing vegetatively through infectious roots at the base of inflorescences. Because of these roots' short length $(2-7 \mathrm{~mm})$, tubers initiated through vegetative reproduction will usually abut the original tuber.

More than 30 native angiospermous tree and shrub species have been confirmed as hosts of dactylanthus, many of which are seral species common in recently disturbed sites or on forest margins (Ecroyd 1996). Determining the actual host specimen, or even species, for a specific dactylanthus individual is usually not possible without harming either, due to their attachment being underground.

\section{Experimental design}

For a detailed description of the experimental design see Holzapfel and Dodgson (2004).

The study site was in Waipapa Ecological Area, Pureora Forest Park, Central North Island $\left(38^{\circ} 27^{\prime} \mathrm{S}\right.$, 
$\left.175^{\circ} 35^{\prime} \mathrm{E}\right)$. Twenty-four sowing plots were established in 1999 on either side of a c. $1 \mathrm{~km}$ length of forestry road, in the ecotone between mature podocarp-hardwood forest and a fire-induced frost flat (Leathwick 1987; Smale 1990). The area was chosen due to the presence of known host species in sufficient abundance, its similar altitude and general vegetation to the closest known dactylanthus population about $6 \mathrm{~km}$ away and absence of dactylanthus at the site (Holzapfel 2005).

Four sowing sites were chosen, each with a single host species prevalent as the dominant canopy-forming tree. Dominant host species were lancewood [Pseudopanax crassifolius (Sol. ex A.Cunn) K. Koch] at two sites, and kohuhu [Pittosporum tenuifolium Sol. ex Gaertn.] and fivefinger [Pseudopanax arboreus (Murray) Philipson] at one site each; other host species were also present at each site in smaller numbers. All sites were considered to provide an adequate level of soil moisture required for the survival and germination of the seeds of dactylanthus, based on Ecroyd (1996) and the authors' familiarity with habitat across the species' range. One of the lancewood-dominated sites had a more open canopy and was assumed to be drier in summer than the other three sites.

At each site, six plots of $50 \times 50 \mathrm{~cm}$ size were established close to adult trees of the targeted host species. Plots were located in pairs, each plot of a pair in close proximity to the other $(10-150 \mathrm{~cm})$. Each pair was placed close $(10-70 \mathrm{~cm})$ to a different potential host tree to maximise exposure to suitable host roots. Plots were permanently marked with aluminium stakes at each corner, allowing the exact placement of a rigid wire-mesh grid-template dividing each plot into 100 squares of $5 \times 5 \mathrm{~cm}$ size, each square with a unique identification code.

Twenty-four infructescences with a moderate to full seed-set (Barkla and Holzapfel 1997) were collected in January 1999 from a single dactylanthus population ('Plains Road') about $6 \mathrm{~km}$ from the sowing site, when seed would have been at least 9-10 months of age and considered mature and viable (Holzapfel 2001). Seeds were cleaned, mixed together, divided into 24 aliquots and sown the following day. One randomly chosen aliquot was counted and contained 1477 seed, i.e. roughly half the average total amount of seed expected on a full seed head (Ecroyd 1996).

Before sowing, plots were cleared of leaf litter and the soil broken up to a depth of c. $5 \mathrm{~cm}$, exposing a dense network of fine roots. A proportion of these were intentionally severed in the process to stimulate rapid re-growth of young roots assumed to be required for a successful attachment of dactylanthus (Moore 1940).

Two sowing methods, 'central' and 'broad', were applied, simulating two observed modes of seed dispersal (Ecroyd 1996; Holzapfel 2001; Moore 1940). In central-sown plots, each seed aliquot was sown onto a single $5 \times 5 \mathrm{~cm}$ grid square at the centre of the plot, simulating the shallow burial of an entire infructescence. In broad-sown plots, each aliquot was spread evenly over the entire $50 \times 50 \mathrm{~cm}$ plot, simulating the spread of seeds from one infructescence over a wider area. Each individual grid-square in broad-sown plots therefore contained about 1/100th of the amount of seed of the central grid-square in central-sown plots.

Both sowing methods were used for each plot pair, allocated randomly for each plot. This resulted in an experimental design of two sowing methods with three replicate plot pairs per site or 12 plots across all sites, and a total of 24 plots. After sowing, the grid template was removed and the leaf litter and soil replaced. Following the first emergence of inflorescences 4 years after sowing, all plots were covered with $19 \mathrm{~mm}$ mesh cages to prevent the loss of inflorescences through browse and minimise pollination to ensure that no additional seed was added to a plot during the trial. Five infructescences developed despite caging and were removed before any seed had been shed.

\section{Monitoring}

All plots were monitored annually over 1 or 2 days within the second half of the flowering season to maximise the detection of inflorescences and buds. Leaf litter on each plot was removed carefully before monitoring and replaced afterwards. Plots were assessed visually only, minimising further soil disturbance due to the exceedingly brittle nature of initial infection stages (Holzapfel 2001). The presence of one or more surface tubers and/or inflorescences was used as confirmation of successful establishment of dactylanthus, acknowledging that non-flowering sub-surface tubers may already have established in years prior to emergence.

The number of surface tubers and the number and sex of inflorescences of the current season were recorded for each $5 \times 5 \mathrm{~cm}$ grid square. 
Inflorescences just outside the actual plot were scored by their nearest grid square and included in the total number for each plot. Where possible, buds were opened to determine their sex; where this was not successful the sex was noted as undetermined.

From 2006 onwards spadices of all inflorescences bearing male flowers at their tip were examined with a hand-lens or microscope for the presence of female flowers at their base. Because female flowers are always arranged below male flowers on monoecious spadices (Cheeseman 1914; Ecroyd 1996; Holzapfel 2001), inflorescences with apical female flowers were not examined. Monoecious inflorescences were included in the total count of either male or female inflorescences for the plot, depending on their predominant sex.

Tubers that were exposed sufficiently to allow accurate measurements were sketched, photographed and measured in the field, and all successful plots were photographed as a record.

\section{Statistical analysis}

Data were analysed with the statistical software R, version 3.2.0, with the associated package lme4 (Bates et al. 2015; R Core Team 2015). Graphs were prepared in MS Excel.

Because of the unbalanced design in regards to canopy status (closed for one site, open for three sites), we examined canopy status as a predictor of establishment success comparing only the two sites which shared lancewood as the same host. Conversely, to assess the dominant host as a predictor, only the three closed-canopy sites were compared. Sowing method as a predictor was included in both analyses.

Flowering (presence and number of inflorescences) was used as a proxy measure for the success of establishment in each plot. Two outcome measures were considered most informative, i.e. the number of inflorescences at year 10 and the total number of inflorescences over the 10-year trial. Both measures are related; early established plants not only would contribute several times to the total count, but would also increase in size from year to year and so produce more inflorescences at year 10 than younger, smaller plants. We analysed both measures but present results for inflorescences at year 10 only, as conclusions were the same for both measures. Data were analysed using a Poisson mixed model with a log link and a random effect to account for pairing of plots on a single host tree. For all results statistical significance was considered at $P$ value 0.05 or below.

\section{Results}

\section{Establishment}

Dactylanthus was first recorded four years after sowing in two plots, showing both tubers and inflorescences and a single inflorescence, respectively. The number of plots with confirmed establishment (tubers and/or inflorescences) increased in each subsequent year until at year ten 22 of 24 plots (93\%) showed dactylanthus being present (Fig. 2, also online resource Table A). Plots with both inflorescences and visible tubers made up the largest proportion of successful plots each year, followed by plots with inflorescences only and tubers only. By year 10, these categories made up 68, 18 and $14 \%$ of successful plots, respectively (Fig. 2). Time to first flowering of successful plots ranged for the four sites from 4 to 7 years for kohuhu (mean 5.5), 4-10 years for fivefinger (mean 6.5), 5-6 years for lancewood with closed canopy (mean 5.5) and 7-8 years for lancewood with open canopy (mean 7.3). For the two sowing densities (plots from all closed-canopy sites combined), time to first flowering was very similar, ranging from 4 to 10 years for central-sown (mean 6.2) and 4-9 years for broad-sown plots (mean 6.1).

\section{Tubers}

Surface tubers numbered on average 2.6 tubers per plot (range $1-14, n=18$ ), their number increasing at least once between monitoring periods in four plots. Tubers ranged from 2 to $45 \mathrm{~mm}$ in diameter (average $21 \mathrm{~mm}, n=38$ ) at first detection. In all cases, emergence of tubers above the soil seemed to be a result of tuber and host-root growth pushing the tuber up rather than disturbance of the plot. Newly emerged tubers showed a characteristic patterning of lightbrown angular platelets surrounded by lighter boundary lines (Fig. 1a). In older tubers the exposed surface became uniformly darker brown and the boundary lines less distinct.

Yearly increase in tuber diameter ranged from 0 to $13 \mathrm{~mm}$, representing $0-76 \%$ of the previous year's 


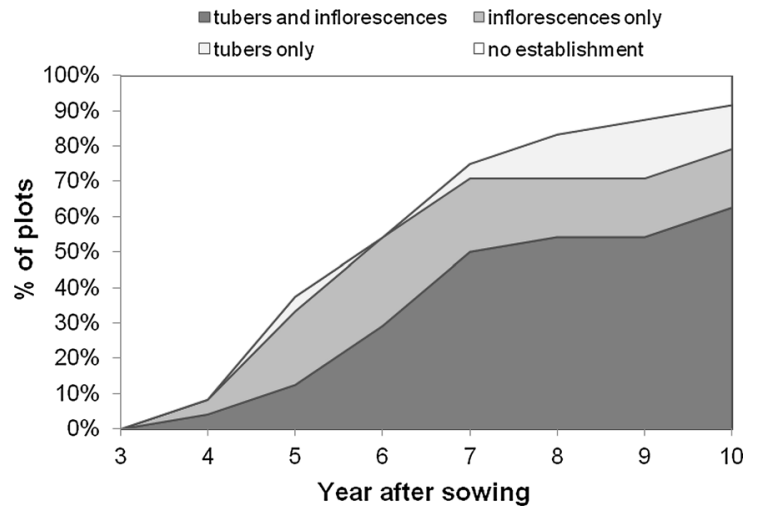

Fig. 2 Establishment of dactylanthus in each year after sowing. Plots were categorised according to whether tubers only, inflorescences only, tubers and inflorescences or no dactylanthus were visible. Data shown from year 3 onwards only, the year before the first plots with dactylanthus, were recorded

diameter. The average increase per year was $6 \mathrm{~mm}$, or $26 \%(n=16)$. Tuber growth was in most cases stronger in the first year after emergence compared to the following year(s). In several cases only a portion of the tuber appeared to grow, leading to a change in its overall shape. These areas of growth appeared calluslike, with light-brown angular stone-cell aggregates but lacking the regular pattern described above for young tubers.

Bud-protuberances, i.e. the earliest visible stage of inflorescence bud development on the tuber surface (Fig. 1a, $c f$. also Holzapfel (2001), were seen on tubers as small as $15 \mathrm{~mm}$ diameter, while the smallest tuber with a fully developed inflorescence was $18 \mathrm{~mm}$ in diameter. Inflorescences fully developed only from the near- or sub-soil portion of tubers; bud protuberances on exposed surfaces did not develop further.

\section{Inflorescence numbers}

The majority of inflorescences emerged from subsurface tubers. From year 4 after sowing onwards the total number of inflorescences (all plots and sites combined) increased each year, to 756 in year 10 and a total of 2602 over the trial (online resource Table B). Inflorescence numbers ranged from 1 to 8 (average 4.2) for plots in their first year of flowering, with the exception of a single plot that produced 16 inflorescences in its first year. The maximum number of inflorescences recorded in a single plot also increased each year, reaching 103 in year 10. In the majority of plots inflorescence numbers increased with each subsequent year of flowering, though the percentage of plots where inflorescence numbers were similar $( \pm 10 \%)$ to the previous year grew as the trial progressed, reaching $42 \%$ at the trial's end.

The closed-canopy kohuhu site produced the highest number of inflorescences, with the mean number per plot and year ranging from 11.3 to 33.3 (median 27.3), followed by the closed-canopy lancewood and fivefinger sites with ranges from 0 to 30.1 (median 7.2) and 0.8 to 18.8 (median 7.6), respectively. The opencanopy lancewood site produced the lowest number of inflorescences, with the mean number per plot ranging from 0 to 1.6 (median 0.3) (Fig. 3).

The mean number of inflorescences per plot for the three closed-canopy sites was similar for both sowing methods in years 4-6 after sowing, after which broadsown plots produced more inflorescences compared to central-sown, reaching a mean of 55.8 and 26.7 per plot, respectively (Fig. 4).

Four plots did not produce inflorescences during the trial, two each in the open and the closed-canopy lancewood sites.

Impact of canopy status, sowing method and dominant host species

For the two sites which shared the same host (lancewood) but differed in canopy status,

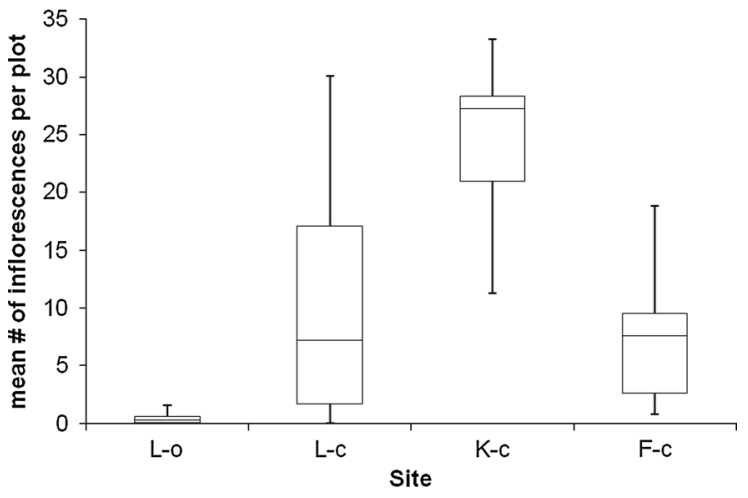

Fig. 3 Box and whisker plots of the mean number of inflorescences per plot at each of the four sowing sites. Results are represented as the median (horizontal line within the box), 25th and 75th quartile (lower and upper boundaries of the box) and lowest and highest values (endpoint of downward and upward whiskers). Sites are: open-canopy dominated by lancewood $(L-o)$, closed-canopy lancewood $(L-c)$, closedcanopy kohuhu $(K-c)$ and closed-canopy fivefinger $(F-c)$ 


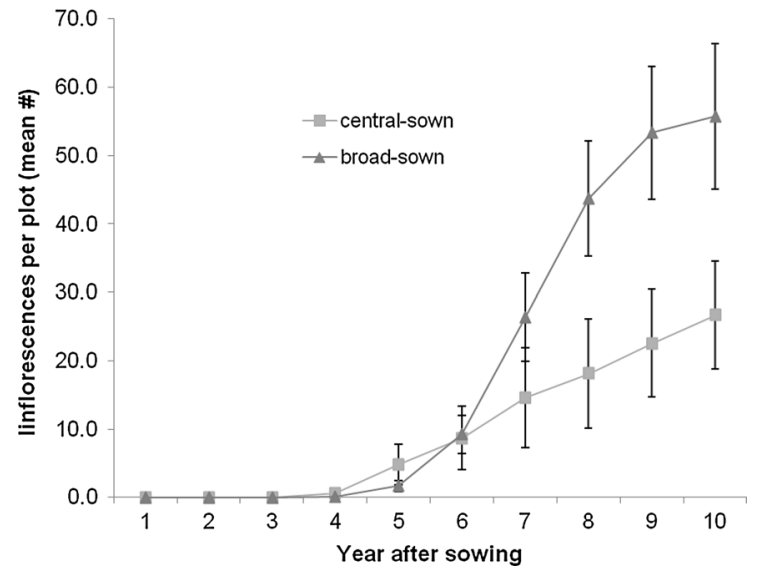

Fig. 4 Comparison of the two sowing methods (central-sown and broad-sown), for the three closed-canopy sites combined. Mean number of inflorescences per plot for each year after sowing are shown. Error bars are $\pm \mathrm{SE}$

inflorescence numbers at year 10 were significantly lower under the open canopy compared to the closedcanopy site. Central sowing resulted in significantly fewer inflorescences compared to broad sowing, across both sites (Table 1). For the three sites that shared the canopy status (closed) but differed in dominant host species, inflorescence numbers at year 10 were significantly fewer for the fivefinger-dominated site but not the lancewood site, compared to the kohuhu site. Central sowing resulted in significantly fewer inflorescences compared to broad sowing, across the three host species (Table 2).

The distribution of inflorescences within plots for each sowing method closely mirrored the initial placement of seeds. In central-sown plots, emergence initially occurred only in close vicinity to the gridsquare into which seed was sown, while in broad-sown plots emergence was spread throughout the plot. This pattern was still discernible in plots in their fourth year of flowering. Inflorescences often emerged in clusters, which grew in subsequent years in size but retained their general position within the plot.

\section{Sex of inflorescences}

The majority of inflorescences was able to be sexed each year, with the percentage of unsexed buds ranging from zero to $49 \%$. Female inflorescences (mean number per plot) increased from 0.3 in year 4 after sowing to 19.8 in year 10 (Fig. 5). Similarly, male inflorescences also increased each year, from zero in year 4 to 9.0 in year 10. While female inflorescences made up the largest proportion of sexed inflorescences each year, this proportion decreased in all but one year after sowing, from $100 \%$ in year 4 to $69 \%$ in year 10 .

Nearly $90 \%$ of plots had only female inflorescences in their first year of flowering (disregarding unsexed buds), with the remaining plots containing only male inflorescences. Female-only plots remained also the largest category for plots in their second and third year of flowering. Nearly $30 \%$ of plots had inflorescences of both sex in their second year of flowering; such mixed-sex plots became the dominant category for plots in their fourth year and the sole category for their fifth and all subsequent years of flowering.

No single-sex plot ever changed into a single-sex plot of the opposite sex from one year to the next; rather, changes were always to mixed-sex plots. Four mixed-sex plots changed into female-only plots from one year to the next, while no such change occurred into male-only plots. In the majority ( $87 \%$ ) of mixedsex plots, male inflorescences first emerged in close proximity to a female inflorescence, either within the same or an adjacent grid square.

Eighteen monoecious inflorescences were found in the 4 years where they were actively searched for (year 7-10 after sowing), in eight unique plots across

Table 1 Influence of canopy status (open, closed) and sowing method (broad-sown, central-sown) on the number of inflorescences per plot at year 10, for the two lancewood-dominated sites. Results are shown for a Poisson mixed-effect model $(n=12)$

\begin{tabular}{lccrc}
\hline & Estimate & Standard error & $t$ value & $P$ value \\
\hline Intercept (closed canopy, broad sowing) & 4.02 & 0.28 & 14.31 & $<0.001$ \\
Open canopy & -2.78 & 0.50 & -5.597 & $<0.001$ \\
Central sowing & -1.84 & 0.20 & -9.40 & $<0.001$ \\
\hline
\end{tabular}


Table 2 Influence of dominant host species (kohuhu, lancewood, fivefinger) and sowing method (broad-sown, centralsown) on the number of inflorescences per plot at year 10, for the three closed-canopy sites. Results are shown for a Poisson mixed-effects model $(n=18)$

\begin{tabular}{lcccc}
\hline & Estimate & Standard error & $z$ value & $P$ value \\
\hline Intercept (kohuhu, broad sowing) & 5.76 & 0.39 & 14.94 & $<0.001$ \\
Fivefinger & -1.57 & 0.55 & -2.85 & $<0.004$ \\
Lancewood & -0.84 & 0.55 & -1.55 & 0.12 \\
Central sowing & -0.68 & 0.04 & -16.41 & $<0.001$ \\
\hline
\end{tabular}

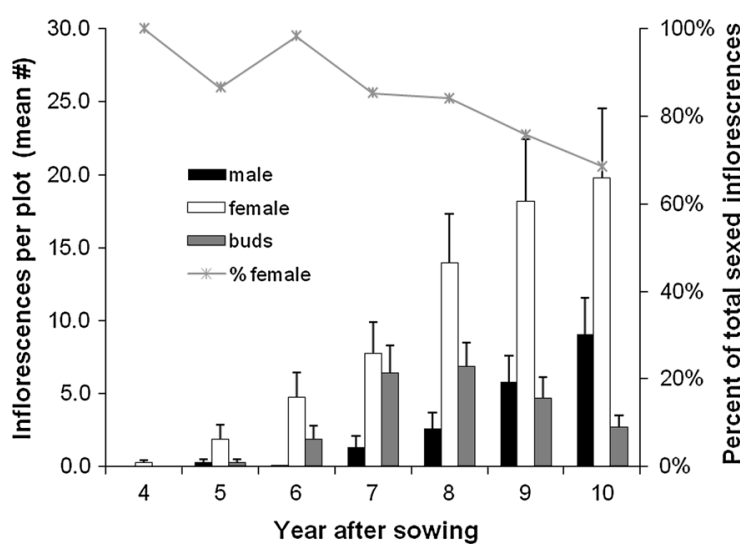

Fig. 5 Sex distribution in plots for each year after sowing. The left axis and bars indicate the mean number of male, female and unsexed (buds) inflorescences per plot. Error bars are + SE. The right axis and line indicate the percentage of female inflorescences of the total of sexed inflorescences. Data shown only from year 4 onwards, when dactylanthus was first recorded in any of the plots

all four sites. Monoecious inflorescences made up zero, $0.5,0.9$ and $1.6 \%$ of all sexed inflorescences in each respective year, or zero, 3.1, 3.5 and $4.8 \%$ of inflorescences with male flowers.

The majority ( $84 \%$ ) of monoecious inflorescences had spadices with only one or few female flowers at their base; for the remainder female flowers made up between 20 and $80 \%$ of all flowers on a spadix.

\section{Discussion}

Establishment

The current study has demonstrated that dactylanthus can be successfully established in the field using conventional sowing methods, contrasting with earlier expectations that this would be difficult (Ecroyd 1995, 1996). A minimum time of four years to first emergence is consistent with previous small-scale and subsequent trials and should be regarded as characteristic for the species (Cashmore 2012; Ecroyd 1995, 1996; Overdyck 2012).

The abundance of inflorescences in most plots and across most sites was comparable to or even exceeding that of wild dactylanthus populations (Ecroyd 1996; Hill 1926), demonstrating that strong, healthy plants had established and thereby satisfying one of the key criteria for translocation success (Monks et al. 2012). Increases in inflorescence numbers appear to have been due to both growth of individual tubers and new tubers becoming established, the former indicated by the growth of defined inflorescence clusters over subsequent years.

The design of the trial did not allow recruitment, at least via seed, by the first-generation individuals, another success criterion for translocations (Dalrymple et al. 2011, 2012). Nevertheless, the large number of inflorescences and the occurrence of some fruit-set despite measures to prevent pollination provide strong confidence that recruitment would occur if pollinators are given access to the inflorescences, as long as browsers are adequately controlled.

Factors influencing establishment

Sowing method, canopy status and dominant host all have had at least some influence on the success of the establishment and flowering of dactylanthus, with broad-sown plots under closed canopy and kohuhu or lancewood as dominant host showing greater success than other combinations in this trial. A number of hypotheses are offered in the following as to the underlying reasons for this influence. 


\section{Sowing method}

Successful initial establishment from seed will depend on the availability in space (distribution and density) and time of both germinating seeds (Fenner 1995; Holzapfel 2001) and suitable host roots (Atsatt 1983). The two sowing methods determined availability of seed differently, maximising it either in space (broadsown) or in time (central-sown). Despite this, both methods appeared to provide similar chances of initial establishment even across three different host species, as indicated by the similarity in time to first flowering. That results differed significantly, on the other hand, for the number of inflorescences at year 10 is interpreted here as an indication that the two methods caused different degrees of intraspecific competition, i.e. crowding between dactylanthus tubers. In centralsown plots, tubers established in closer proximity to each other compared to broad-sown plots. As these tubers grew in size and numbers, it can be expected that an increasingly large proportion of their surfaces would not be exposed to soil anymore but instead abut tightly to the surface of neighbouring tuber(s). Inflorescences in dactylanthus originate endogenously and push through the tuber cortex (Hill 1908; Holzapfel 2001; Moore 1940), with inflorescence numbers increasing as the tuber grows in size. Consequently, a reduction in surface area exposed to soil will result also in a reduction of inflorescences compared a similar-sized unobstructed tubers. This would become more prominent as tubers grow and seal off increasingly larger areas of tuber surface in clumped tubers, which is consistent with the increasing difference in inflorescence numbers between both methods as the trial progressed.

\section{Canopy status}

The overall low success at the open-canopy site is interpreted here to be due to the expected higher soilmoisture stress compared with an otherwise similar, closed-canopy site, in particular during summer and drought periods (Martius et al. 2004; Yavitt and Wright 2001). This would have increased mortality of the desiccation-vulnerable dactylanthus seed (Holzapfel 2001) and decreased the density of young roots in the upper soil layer (Persson et al. 1995; Persson 1983; Yavitt and Wright 2001), reducing the probability of successful infections in the sowing plots. The importance of adequate soil moisture as a critical determinant for dactylanthus establishment is also reflected in populations of dactylanthus being generally under moderately dense forest cover and on sites that are not drought-prone (Ecroyd 1996).

\section{Dominant host}

Differences in establishment and growth at the three closed-canopy sites indicate further site-specific, in particular host-specific, preferences for dactylanthus, with kohuhu and lancewood appearing to be more productive hosts compared to fivefinger. Our methods did not allow us to confirm the identity of the actual infected roots. Close proximity to a specific host stem has been shown to determine availability of roots from that tree for another root holoparasite Thonningia sanguina Vahl (Balanophoraceae s.str.) (Olanya and Eilu 2009), however, at least some infections in our plots may have been on roots of a different host species nearby rather than the targeted one (Marden et al. 2005). Assuming that such infections are in the minority and no other site-specific factors have influenced the outcome unduly, results indicate that the wide host range of dactylanthus (Ecroyd 1996; Moore 1940) does not translate to an equal preference for different hosts. This is in line with findings for other holoparasitic plants (Atsatt 1983; Gibson and Watkinson 1989; Marvier and Smith 1997; Press and Phoenix 2005) and would be a first step to identify principal and minor hosts of dactylanthus (Atsatt 1983; Pennings and Callaway 2002). Host preference may be due to both pre-infection and post-infection factors, where the former determines availability of suitable roots in space and time and the latter the physiological 'match' (Atsatt 1983; Press and Phoenix 2005) between host (species or individual) and parasite (Pennings and Callaway 2002; Watson 2009).

\section{Sex distribution}

One surprising finding was the scale and consistency of dominance of female inflorescences, observed also in subsequent trials (Cashmore 2012; Overdyck 2012), and an increasing of the male proportion in successive years. Female dominance strongly contrasts with that of longer-established wild populations, where male usually far outnumber female inflorescences. While dactylanthus is generally regarded as dioecious 
(Ecroyd 1996; Harms 1935; Holzapfel 2001; Hooker 1859; Moore 1940, but see Cheeseman 1920), these results and the close proximity of male and female inflorescences in mixed-sex plots challenge this assumption. On the other hand, no clear evidence is provided in the literature for claims of monoecy in the species, apart from the rare occurrence of monoecious inflorescences at least demonstrating sexual bi-potency in mature individuals (Dellaporta and CalderonUrrea 1993).

Rather than interpreting results in light of fixed sexuality of individuals, we suggest that they could be seen as indications of dactylanthus as a dioecious species with labile sex, environmental sex determination (ESD) and associated sex change of individuals (Dellaporta and Calderon-Urrea 1993; Freeman et al. 1980 and references therein). Resource availability has been identified as one factor for ESD (Freeman et al. 1980), with increased resources often linked to a higher percentage of the female form of a species. For the holoparasitic dactylanthus resources are solely determined by the host tree, therefore, the early dominance of female inflorescences and a change to male dominance could indicate a worsening of supply from host to parasite over time since the initial infection. Causes could include an increasing of host defence mechanisms, or the growth of dactylanthus and corresponding demand for nutrients and water outstripping the host's ability to supply these. Plots with male inflorescences in their first year of emergence may indicate a weaker or less suitable host or individual root.

Regardless of the underlying determinants of sexuality, female dominance early after establishment, combined with a wide-ranging pollinator such as the short-tailed bat (Cummings et al. 2014), will result in a larger seed-set and hence a more rapid spread of individuals at a new site than if genders would be equally distributed or male-skewed. This will benefit the establishment of dactylanthus, given its naturally fragmented populations and dependence mainly on seral host species.

\section{Conclusion}

The present study has demonstrated that dactylanthus can be sown directly into suitable habitat to establish strong populations, with the expectation that these will be viable long-term.
It has highlighted aspects, including evidence of host preference and the importance of sufficient soil moisture for establishment, which will make conservation management for the species more targeted. The abundance of female inflorescences in newly established populations will be a welcome relief for conservation managers, creating an immediate source for dactylanthus seed for further translocations (Ecroyd 1996; La Cock et al. 2005). It will also allow for a better assessment of the recruitment status, and therefore health, of populations of unknown age, providing a further tool to establish base-line information and monitor the impact of protection measures.

Findings are sufficiently robust to recommend similar trials also for other rare or threatened holoparasitic plants globally, alongside the more traditional focus on preservation of existing populations and their hosts (Marvier and Smith 1997; Olanya and Eilu 2009). The methods developed here not only provide new and important conservation tools for dactylanthus, but can be adapted also for other threatened parasitic plants.

Acknowledgments This study would not have been possible without the assistance of numerous Department of Conservation staff members and volunteers over more than a decade of field work. SAH gratefully acknowledges the support and encouragement of his successive managers and the dactylanthus Recovery Group, the hospitality, enthusiasm and logistical support of Pureora Field Centre staff, Vicki Wilson for uncounted hours of data entry and David Mudge and Nga Manu Trust for the use of the image in Fig. 1. Comments by Graeme la Cock, Chris Ecroyd, Jennifer Germano, Peter de Lange, Carol West and Paul van Dam-Bates, as well as formal peer reviews by Dave Kelly and Daniel Nickrent greatly improved earlier versions of the manuscript.

Open Access This article is distributed under the terms of the Creative Commons Attribution 4.0 International License (http:// creativecommons.org/licenses/by/4.0/), which permits unrestricted use, distribution, and reproduction in any medium, provided you give appropriate credit to the original author(s) and the source, provide a link to the Creative Commons license, and indicate if changes were made.

\section{References}

Arunachalam A, Adhikari D, Sarmah R, Majumder M, Khan ML (2004) Population and conservation of Sapria himalayana Griffith. in Namdapha national park, Arunachal Pradesh, India. Biodivers Conserv 13:2391-2397 
Atsatt PR (1983) Host-parasite interactions in higher plants. In: Lange OL, Nobel PS, Osmond CB, Ziegler H (eds) Physiological plant ecology III. Springer, Berlin, pp 519-535

Barkla J, Holzapfel AS (1997) Dactylanthus recognition sheet. Department of Conservation, Wellington

Bates D, Maechler M, Bolker B. and Walker S (2015) Fitting linear mixed-effects models using lme4. J Stat Softw 67: 1-48. URL: http://CRAN.R-project.org/package=lme4

Bolin JF, Maass E, Tennakoon KU, Musselman LJ (2009) Hostspecific germination of the root holoparasite Hydnora triceps (Hydnoraceae). Botany 87:1250-1254

Cashmore P (2012) Dactylanthus recovery group 2012 annual report. Department of Conservation, Rotorua

Cheeseman TF (1906) Manual of the New Zealand Flora. John Mackay, Wellington

Cheeseman TF (1914) Illustrations of the New Zealand Flora. John Mackay, Wellington

Cheeseman TF (1920) Contributions to a further knowledge of the flora of New Zealand No. 7. Trans Proc N. Z. Inst 52:9-16

Cummings G, Anderson S, Dennis T, Toth C, Parsons S (2014) Competition for pollination by the lesser short-tailed bat and its influence on the flowering phenology of some New Zealand endemics. J Zool 293:281-288

Dalrymple S.E., Stewart G.B. and Pullin A.S. (2011) Are reintroductions an effective way of mitigating against plant extinctions? Collaboration for Environmental Evidence. www.environmentalevidence.org/SR32.html

Dalrymple SE, Banks E, Stewart GB, Pullin AS (2012) A metaanalysis of threatened plant reintroductions from across the globe. In: Maschinski J, Haskins KE (eds) Plant reintroduction in a changing climate. Island Press, Washington, pp 31-50

de Lange PJ, Rolfe JR, Champion PD, Courtney SP, Heenan PB, Barkla JW, Cameron EK, Norton DA, Hitchmough RA (2013) Conservation status of New Zealand indigenous vascular plants, 2012. Department of Conservation, Wellington

Dellaporta SL, Calderon-Urrea A (1993) Sex determination in flowering plants. Plant Cell 5:1241-1251

Ecroyd CE (1995) Dactylanthus and bats: the link between two unique endangered New Zealand species and the role of the community in their survival. In: Saunders DA, Craig JL, Mattiske EM (eds) Nature conservation 4: the role of networks. Surrey Beatty \& Sons, Sydney, pp 78-87

Ecroyd CE (1996) The ecology of Dactylanthus taylorii and threats to its survival. N. Z. J Ecol 20:81-100

Fenner M (1995) Ecology of seed banks. In: Kigel J, Galili G (eds) Seed development and germination. Marcel Dekker Inc, New York, pp 507-528

Freeman DC, Harper KT, Charnov EL (1980) Sex change in plants: old and new observations and new hypotheses. Oecologia 47:222-232

Gibson CC, Watkinson AR (1989) The host range and selectivity of a parasitic plant: Rhianthus minor L. Oecologia 78:401-406

Harms H (1935) Balanophoraceae. In: Engler A, Harms H (eds) Die natürlichen Pflanzenfamilien. Wilhelm Engelmann, Leipzig, pp 296-337

Heinricher E (1907) Beiträge zur Kenntnis der Gattung Balanophora. Sitzungsberichte der kaiserlichen Akademie der Wissenschaften in Wien 116:439-465
Heinricher E (1917) Die erste Aufzucht einer Rafflesiacee, Cytinus Hypocistis L., aus Samen. Berichte der deutschen botanischen Gesellschaft 35:505-512

Hill H (1908) On Dactylanthus Taylori. Trans N. Z. Inst 41:437-440

Hill H (1926) Dactylanthus Taylori. Trans N. Z. Inst 56:87-90

Holzapfel S (2001) Studies of the New Zealand root-parasite Dactylanthus taylorii (Balanophoraceae). Englera 22:7-176

Holzapfel S (2005) Dactylanthus taylorii recovery plan review: 1995-2000. Department of Conservation, Wellington

Holzapfel AS, Dodgson J (2004) Experimental seeding trials for the root parasite Dactylanthus taylorii. Department of Conservation, Wellington

Holzapfel S, Faville MZ, Gemmill CEC (2002) Genetic variation of the endangered holoparasite Dactylanthus taylorii (Balanophoraceae) in New Zealand. J Biogeogr 29:663-676

Hooker JD (1859) On a new genus of Balanophoraceae from New Zealand, and two new species of Balanophora. Trans Linn Soc Lond 22:425-428

Joel DM, Steffens JC, Matthews DE (1995) Germination of weedy root parasites. In: Kigel J, Galili G (eds) Seed development and germination. Marcel Dekker Inc, New York, pp 567-597

Kuijt J (1969) The biology of parasitic flowering plants. University of California Press, Berkeley

La Cock GD, Holzapfel S, King D, Singers N (2005) Dactylanthus taylorii recovery plan, 2004-2014. Department of Conservation, Wellington

Lawrence BA, Kaye TN (2008) Direct and indirect effects of host plants: implications for reintroduction of an endangered hemiparasitic plant (Castellia levisecta). Madroño 55:151-158

Leathwick JL (1987) Waipapa Ecological Area: A study of vegetation pattern in a scientific reserve. Ministry of Forestry, Rotorua

Marden M, Rowan D, Phillips C (2005) Stabilising characteristics of New Zealand indigenous riparian colonising plants. Plant Soil 278:95-105

Martius C, Höfer H, Garcia MVB, Römbke J (2004) Microclimate in agroforestry systems in central Amazonia: does canopy closure matter to soil organisms? Agrofor Syst 60:291-304

Marvier MA (1996) Parasitic plant-host interactions: plant performance and indirect effects on parasite-feeding behaviour. Ecology 77:1398-1409

Marvier MA, Smith DL (1997) Conservation implications of host use for rare parasitic plants. Conserv Biol 11:839-848

Mescher MC, Smith J, de Moraes CM (2009) Host location and selection by holoparasitic plants. In: Baluška F (ed) Plantenvironment interactions. Springer, Berlin, pp 101-118

Meys AJ (2003) The role of introduced mammals in seed predation and dispersal of Dactylanthus taylorii Hook.f. Environmental and Marine Science. University of Auckland, Auckland

Ministry for the Environment (2007) Environment New Zealand 2007. Ministry for the Environment, Wellington

Monks L, Coates D, Bell T, Bowles M (2012) Determining success criteria for reintroductions of threatened long-lived plants. In: Maschinski J, Haskins KE (eds) Plant reintroduction in a changing climate. Island Press, Washington, pp 189-208 
Moore LB (1940) The structure and life-history of the root parasite Dactylanthus taylori Hook.f. N. Z. J Sci Technol 21:206B-224B

Musselman LJ, Press MC (1995) Introduction to parasitic plants. In: Press MC, Graves JD (eds) Parasitic plants. Chapman \& Hall, London, pp 1-13

Olanya CA, Eilu G (2009) Host-parasite relations of an angiospermous root parasite (Thonningia sanguinea Vahl) in logged and unlogged sites of Budongo forest reserve, western Uganda. Afr J Ecol 47:328-334

Overdyck E (2012) Dactylanthus taylorii flowers in threatened plant garden. N. Z. Bot Soc Newsl 109:11

Pennings SC, Callaway RM (2002) Parasitic plants: parallels and contrasts with herbivores. Oecologia 131:479-489

Persson HA (1983) The distribution and productivity of fine roots in boreal forests. Plant Soil 71:87-101

Persson H, Von Fircks Y, Majdi H, Nilsson LO (1995) Root distribution in a Norway spruce (Picea abies (L.) Karst.) stand subjected to drought and ammonium-sulphate application. Plant Soil 168-169:161-165

Press MC, Graves JD (eds) (1995) Parasitic plants. Chapman \& Hall, London

Press MC, Phoenix GK (2005) Impacts of parasitic plants on natural communities. New Phytol 166:737-751

Shen H, Ye W, Hong L, Huang H, Wang Z, Deng X, Yang Q, Xu $Z$ (2005) Progress in parasitic plant biology: host selection and nutrient transfer. Plant Biol 8:175-185

Smale MC (1990) Ecology of Dracophyllum subulatum-dominant heathland on frost flats at Rangitaiki and north
Pureora, central North Island, New Zealand. NZ J Bot 28:225-248

Stewart GR, Press MC (1990) The physiology and biochemistry of parasitic angiosperms. Annu Rev Plant Physiol Mol Biol 41:127-151

Su H-J, Hu J-M, Anderson FE, Nickrent DL (2015) Phylogenetic relationships of Santalales with insights into the origins of holoparasitic Balanophoraceae. Taxon 64:491-506

R Core Team (2015) R: A language and environment for statistical computing. R Foundation for Statistical Computing. Vienna. http://www.R-project.org/

Watanabe K (1942) Morphologisch-biologische Studien über Balanophoraceen in Nippon ausgenommen Taiwan (4). J Jpn Bot 18:438-446

Watson DM (2009) Determinants of parasitic plant distribution: the role of host quality. Botany 87:16-21

Weber HC, Forstreuter W (eds) (1987) Parasitic flowering plants in: Proceedings of the 4th international symposium on parasitic flowering plants. Philipps-Universität, Marburg

Wood JR, Wilmshurst JM, Worthy TH, Holzapfel AS, Cooper A (2012) A lost link between a flightless parrot and a parasitic plant and the potential role of coprolites in conservation paleobiology. Conserv Biol 26:1091-1099

Yavitt JB, Wright SJ (2001) Drought and irrigation effects on fine root dynamics in a tropical moist forest, Panama. Biotropica 33:421-434 